$4-1-2018$

\title{
Making a case for cardiorespiratory fitness surveillance among children and youth
}

Justin J. Lang

Grant Tomkinson

University of North Dakota, grant.tomkinson@und.edu

Ian Janssen

Jonatan R. Ruiz

Francisco B. Ortega

See next page for additional authors

How does access to this work benefit you? Let us know!

Follow this and additional works at: https://commons.und.edu/ehb-fac

Part of the Health and Physical Education Commons

\section{Recommended Citation}

Justin J. Lang, Grant Tomkinson, lan Janssen, et al.. "Making a case for cardiorespiratory fitness surveillance among children and youth" (2018). Education, Health \& Behavior Studies Faculty Publications. 31.

https://commons.und.edu/ehb-fac/31

This Article is brought to you for free and open access by the Department of Education, Health \& Behavior Studies at UND Scholarly Commons. It has been accepted for inclusion in Education, Health \& Behavior Studies Faculty Publications by an authorized administrator of UND Scholarly Commons. For more information, please contact und.commons@library.und.edu. 


\section{Authors}

Justin J. Lang, Grant Tomkinson, Ian Janssen, Jonatan R. Ruiz, Francisco B. Ortega, Luc Léger, and Mark S. Tremblay

This article is available at UND Scholarly Commons: https://commons.und.edu/ehb-fac/31 


\title{
Making a Case for Cardiorespiratory Fitness Surveillance Among Children and Youth
}

Justin J. Lang, 1 Grant R. Tomkinson, Ian Janssen, Jonatan R. Ruiz, Francisco B. Ortega, Luc Leger, and Mark S. Tremblay

\begin{abstract}
We review the evidence that supports cardiorespiratory fitness (CRF) as an important indicator of current and future health among school-aged children and youth, independent of physical activity levels. We discuss the merit of CRF measurement for population health surveillance and propose the development of CRF guidelines to help support regional, national, and international surveillance efforts.
\end{abstract}

\section{INTRODUCTION}

Worldwide, the average life expectancy at birth increased from $61.7 \mathrm{yr}$ in 1980 to $71.8 \mathrm{yr}$ in $2015\left(^{1}\right)$. This improvement has not been matched with equivalent gains in healthy life expectancy (i.e., life expectancy in good health without noncommunicable disease $[\mathrm{NCD}$ ] or disability), creating a situation where individuals are now living longer with comorbidities and disabilities $\left({ }^{2}\right)$. This reality and resulting need for costly treatments has created financial strain on health-care systems and economies across the world. The World Economic Forum has estimated that current NCD projections will result in a cumulative US $\$ 47$ trillion in lost economic production and health-care costs worldwide between 2011 and $2030{ }^{3}$ ). Physical activity (PA) and cardiorespiratory fitness (CRF) represent important modifiable risk factors that have been linked to preventing the global burden of NCD from coronary heart disease, type 2 diabetes, and breast and colon cancer $\left(^{4-6}\right)$. As a result, there is a need to shift toward a cost-effective, population-based, NCD prevention paradigm through effective interventions and policies that promote healthy active living.

Research demonstrates that many NCD risk factors manifest in childhood $\left(^{7}\right)$, suggesting that NCD prevention initiatives should begin during these years. In several countries, there is evidence of temporal declines in certain PA domains (i.e., active transport, physical education, and organized sports $\left({ }^{8-10}\right)$ ), PA across the life course $\left({ }^{11}\right)$, CRF levels $\left({ }^{12}\right)$, and strength $\left({ }^{13}\right)$ and increases in sedentary behaviors and screen time $\left({ }^{14}\right)$ among children and youth over recent decades - supporting the need for health- promoting policies and interventions to help reverse these deleterious trends. It has been argued that a key component of a national strategy to deal with NCD burden is a sustainable population healthsurveillance system that can quantify and monitor NCD risk and the associated determinants $\left({ }^{15}\right)$. Surveillance systems are especially important in guiding and evaluating health-promoting policies and interventions.

Among children and youth, the surveillance of PA levels has emerged as a primary measure to track and compare pediatric health across regions, countries, and cities $\left({ }^{16}\right)$. It is possible that the elevation of PA to a primary surveillance indicator was partly attributable to the development and distribution of PA guidelines that provided recommendations on the amount of PA needed for health promotion. Although the importance of PA has been recognized in surveillance efforts, the same cannot be said for CRF, despite the fact that the CRF level of children and youth is an important indicator of current $\left({ }^{17}\right)$ and future health $\left({ }^{18}\right)$ independent of PA $\left({ }^{19}\right)$. Indeed, it has been suggested that CRF should be included as a measure for national and international health surveillance efforts in young individuals, similar to the surveillance of PA $\left({ }^{20-22}\right)$. Thus, the objective of this review was to examine the utility of the 20-m shuttle run test (20mSRT) - a feasible, valid $\left({ }^{23-25}\right)$, and reliable $\left({ }^{26-28}\right)$ field-based measure of $\mathrm{CRF}$ in children and youth - as a population health surveillance indicator. We start by discussing the importance of CRF as a measure of health among children and youth. We then discuss novel strategies for CRF surveillance, including the importance of establishing guidelines as an effective knowledge translation tool at the population level. Finally, we provide recommendations that may help progress the international utility of CRF as a population 
health surveillance indicator.

\section{CARDIORESPIRATORY FITNESS AND PHYSICAL ACTIVITY}

In 1994, Bouchard and Shephard $\left({ }^{29}\right)$ published a conceptual model that described the relation among health-related fitness, PA, and health for adults. Our modified model for children and youth, as illustrated in Figure 1, describes PA as a behavior that takes place during active play, organized sport, active transportation, and school-based activities. PA behaviors are closely interconnected with a variety of health-related fitness traits that include but is not limited to CRF (i.e., morphological, muscular, motor, and metabolic). The strength of the relation between habitual PA and CRF often has been characterized as small to moderate, although the strength of the relation improves when higher PA intensities are isolated $\left({ }^{30,31}\right)$. Both PA and CRF are influenced by heredity, other lifestyle behaviors such as diet, personal attributes such as age and sex, and exposures to physical and social environments.

Among adults, the surveillance of wellness, morbidity, and mortality provides important health outcomes and allows for vital data to help inform and guide healthy public policy. However, among children and youth, the surveillance of lifestyle-related NCDs (e.g., type 2 diabetes, ischemic heart disease) and related deaths are not common practice because these are rare conditions $\left({ }^{32}\right)$. Rather, surveillance in the pediatric population focuses on risk factors for NCDs, such as obesity, and their upstream determinants, such as PA and, to a lesser extent, CRF.

\section{Cardiorespiratory Fitness Measurement}

$\mathrm{CRF}$ is described as a trait that represents the ability to deliver oxygen to the muscles and to use it to produce energy to support muscle activity during physical activity and exercise $\left({ }^{20,33}\right)$. The measurement of CRF has an extensive history

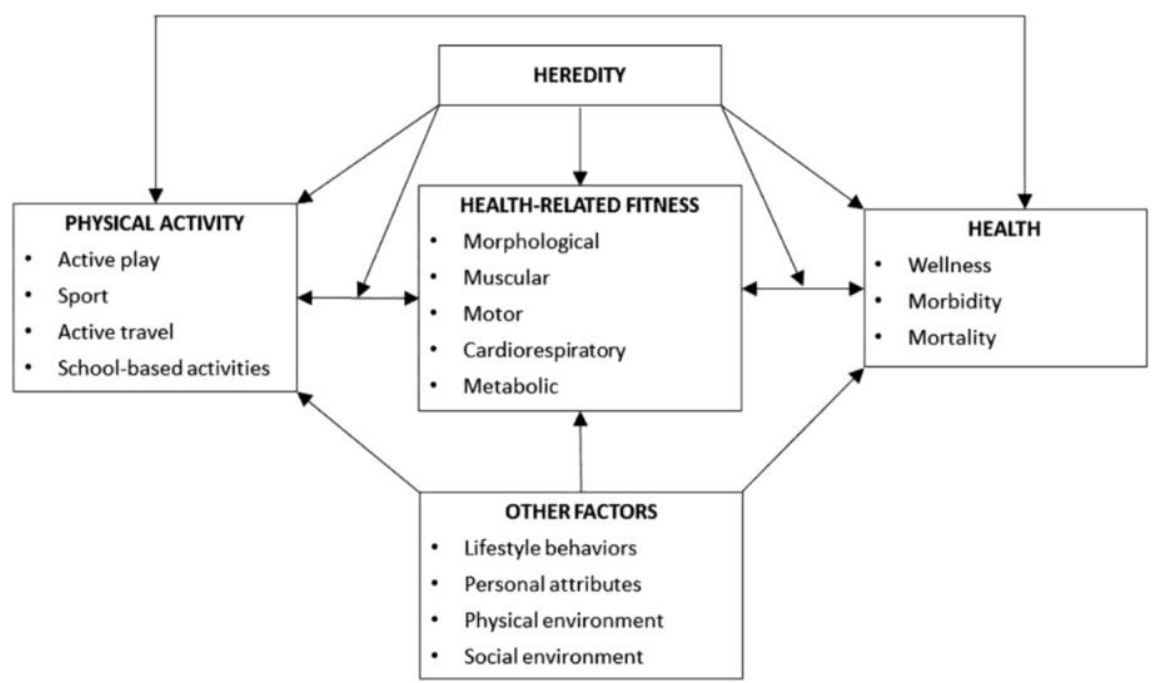

Figure 1. Modified version of Bouchard and Shephard's health-related fitness, physical activity, and health model. [Adapted from $\left({ }^{29}\right)$. Copyright (C) 1994 Human Kinetics. Used with permission].

and is likely one of the most widely reported physiological variables in the field of pediatric exercise science ${ }^{(34-36)}$, yet our understanding of the measurement of CRF remains incomplete. Most measures of CRF are objective for children and youth, with only one known subjective measure of CRF (i.e., International Fitness Scale [IFIS] ${ }^{37,38}$ )). These objective CRF measures can be broadly categorized into laboratory-based and field-based assessments $\left({ }^{26}\right)$.

Laboratory-based assessments of CRF using indirect calorimetry provide a valid measure of peak oxygen uptake $\left(\dot{\mathrm{V}} \mathrm{O}_{2 \text { peak }}\right)$, which is considered the criterion standard measure of CRF in children and youth. In young populations, $\dot{\mathrm{V}} \mathrm{O}_{2 \text { pak }}$ often is used instead of $\mathrm{VO}_{2 \max }$ to describe a maximal effort because these populations often don't attain the 
same plateau in oxygen uptake seen in adults $\left({ }^{39}\right)$. The measurement of $\dot{\mathrm{V}} \mathrm{O}_{2 \text { peak }}$ is an important physiological variable that can be calculated in absolute terms as $\mathrm{L} \cdot \mathrm{min}^{-1}$ values, or in relative terms, typically controlled for body mass and calculated as $\mathrm{mL} \cdot \mathrm{kg}^{-1} \cdot \mathrm{min}^{-1}$ values $\left({ }^{40}\right)$. Both calculations produce varying results; however, controlling for body mass seems to be preferred given that this method is a stronger predictor of health, although fat mass may confound the interpretation of CRF $\left({ }^{41,42}\right)$. Among children and youth, the use of allometric scaling also has been proposed as a favorable method $\left({ }^{43}\right)$. Because laboratory-based assessments have many limitations, such as the need for expensive equipment, specialized human resources, high participant burden, and the time-consuming nature of the assessments, they typically are not feasible for population-based surveillance.

A variety of field-based assessments have been developed to predict $\dot{V}_{2 p a k}$ (e.g., distance runs, endurance shuttle runs), and these field-based assessments provide reasonably accurate estimates $\left({ }^{25,26}\right)$. Of the field-based CRF assessments, the 20mSRT is the most common assessment used worldwide. Originally developed in the 1980s by Leger et al. $\left({ }^{44,45}\right)$, the 20mSRT has since been used to assess CRF in children and youth across more than 50 countries $\left({ }^{12,26,46-48}\right)$ and more than 3 million kids in the United States alone $\left({ }^{49}\right)$. In the 20mSRT, participants are asked to run back and forth between shuttles (i.e., two parallel lines $20 \mathrm{~m}$ apart) after a repeated audio signal beep that begins at a pace of $8.5 \mathrm{~km} \cdot \mathrm{h}^{-1}$ and increases by $0.5 \mathrm{~km} \cdot \mathrm{h}^{-1}$ every stage (i.e., 1-min duration) ${ }^{44,45}$ ). The number of shuttles a child is able to complete provides an estimate of their CRF. The 20mSRT assessment is appropriate for population-based surveillance for a number of reasons including the flexibility of testing environments (indoor, outdoor, small testing area), simplicity of testing procedures, easily interpretable results, no need for specialized human resources, low cost, and ability to test large groups of children simultaneously with relatively low participant burden $\left({ }^{18,26}\right)$. The $20 \mathrm{mSRT}$ also demonstrates a moderate-to-high criterion-related validity $\left({ }^{23-25}\right)$ and high reliability $\left({ }^{26-28}\right)$, suggesting it is a good field-based measure of CRF. The major scientific concern of the $20 \mathrm{mSRT}$ is that it does not provide a direct and isolated assessment of $\dot{\mathrm{V}} \mathrm{O}_{2 \text { peak }}$, but rather, performance on the test is likely a combination of multiple factors including running economy, $\dot{\mathrm{V}} \mathrm{O}_{2 \mathrm{peak}}$ kinetics, fractional usage of oxygen, fat mass, lactate threshold, anaerobic capacity, and psychosocial factors such as motivation, self-efficacy, and pacing ${ }^{26}$ ). This suggests that laboratory- based and field-based assessments measure slightly different aspects of the CRF construct. Thus, researchers have debated whether 20mSRT performance values should be reported as raw values (i.e., laps, stages), or converted to $\mathrm{U}^{\prime} \mathrm{O}_{2}$ peak $\left(\mathrm{mL} \bullet \mathrm{kg}^{-1} \bullet \mathrm{min}^{-1}\right.$ ) given that the prediction equation applied introduces additional error to the estimate $(24,50,51)$. To our knowledge, there are at least five published equations available to predict $\dot{\mathrm{V}}_{2}$ peak using $20 \mathrm{mSRT}$ scores $\left({ }^{45,52-55}\right)$ (Table 1), all of which differ in validity and would produce different $\dot{\mathrm{V}}_{2}$ peak estimates, creating a need for consensus on a standardized equation in this field. However, as discussed later, the decision to use raw values instead of predicted $\dot{\mathrm{V}}_{2}$ peak values has implications related to health-related and performance-related fitness.

The use of raw 20mSRT values (i.eshuttles, stages, running speed $\left[\mathrm{km} \bullet \mathrm{h}^{-1}\right]$ at the last completed stage) provides the best estimate of CRF performance, and raw values have been widely used in the development of normativereferenced standards $\left({ }^{47,56-63}\right)$. The use of normative-referenced standards to provide an interpretation of $20 \mathrm{mSRT}$ scores is a reflection of performance-related fitness. Normative- referenced standards provide a relative interpretation of $20 \mathrm{mSRT}$ performance by determining centile ranks in comparison with peers of the same age and sex $\left({ }^{64}\right)$, making it is possible to identify high, average, or low 20mSRT performance. The primary limitation of this approach is that normative- referenced standards are not linked to a health outcome. In contrast, criterion-referenced standards identify the minimum amount of CRF needed for good health, with several different standards emerging in the literature over the past $10 \mathrm{yr}\left({ }^{64-69}\right)$. Although criterion-referenced standards represent a way to identify the percentage of healthy children and youth in a population, a major limitation is that these standards do not readily allow for the use of raw 20mSRT performance scores. The reason for this limitation is that the majority of criterionreferenced standards have been developed using a variety of 


\begin{tabular}{|c|c|c|c|}
\hline Citation (publication year) & Sample & Country & Equation to Estimate $\mathrm{V}^{0} 2_{\mathrm{pi}}, \mathrm{j}<$ \\
\hline \multirow{2}{*}{$\begin{array}{l}\text { Lfger(45) } \\
\text { Barnett (52) }\end{array}$} & \multirow{2}{*}{$\begin{array}{l}188 \text { boys and girls, aged } 8-19 \mathrm{yr} \\
27 \text { boys, } 28 \text { girls, aged } 12-17 \mathrm{yr}\end{array}$} & \multirow{2}{*}{$\begin{array}{l}\text { Canada } \\
\text { Hong Kong }\end{array}$} & VOipck $=31.025+3.238-\mathrm{S}-3.248-\mathrm{A}+0.1536 \mathrm{~S} \mathrm{~A}$ \\
\hline & & & $\begin{aligned} \text { VOzpcak } & =25.8-6.6-\mathrm{Gj}-0.2-\mathrm{W}+3.2-\mathrm{S} \\
\mathrm{V0}_{21}{ }^{*}, \mathrm{k} & =24.4-5.0-\mathrm{G},-0.8-\mathrm{A}+3.4 \mathrm{~S}\end{aligned}$ \\
\hline $\begin{array}{l}\text { Matsuzaka (53) } \\
\text { Mahar (54) }\end{array}$ & $\begin{array}{l}62 \text { boys, } 70 \text { girls, aged } 8-17 \mathrm{yr} \\
61 \text { boys, } 74 \text { girls, aged } 12-14 \mathrm{yr}\end{array}$ & $\begin{array}{c}\text { Japan } \\
\text { United States }\end{array}$ & $\begin{array}{c}\mathrm{VD}_{2 \text { pcak }}=25.9-2.21-\mathrm{G},-0.449-\mathrm{A}-0.831 \mathrm{BM} 1+4.12-\mathrm{S} \\
\mathrm{VOz}^{\wedge} \mathrm{ak}-47.438+\mathrm{L}-0.242+\mathrm{G}_{2}-5.134-\mathrm{W}-0.197\end{array}$ \\
\hline Ruiz (55) & 122 boys, 71 girls, aged $13-19 \mathrm{yr}$ & Spain & Artificial neural network equation available: http://www.helenastudy.com/scientific.php \\
\hline
\end{tabular}

A, indicates participant's age at hist birthday; BM/, body mass index $\left(\mathrm{kg} / \mathrm{m}^{2}\right)$; Gj, sex (male = 0, female = 1); G2, sex (female = 0, male = 1); L, number of laps completed; $\mathrm{S}$, running speed $\left(\mathrm{k} \mathrm{m} \mathrm{h}^{1}\right)$ at the last completed stage; and $W$, body weight $(\mathrm{kg})$. Peak oxygen uptake, $\mathrm{V0}_{2 \mathrm{pcik}} \mathrm{-}$

laboratory-based assessments of direct and indirect measured $\dot{\mathrm{V}} \mathrm{O}_{2}$ peak, resulting in the standards almost always being reported as $\mathrm{mL} \cdot \mathrm{kg}^{-1} \cdot \mathrm{min}^{-1}$ values. Thus, there is a need to convert $20 \mathrm{mSRT}$ scores to a common metric, $\dot{\mathrm{VO}}_{2 \text { peak }}$, or the standards themselves must be converted to $20 \mathrm{mSRT}$ raw values. In essence, health-related and performance-related fitness have emerged as two separate ideologies on how to interpret CRF results. However, the use of normative-referenced and criterion-referenced standards is not mutually exclusive, and in fact, these approaches complement each other well. Thus, both methods could potentially coexist, and should be reported, in population-based CRF surveillance efforts.

\section{HEALTH INDICATORS AMONG CHILDREN AND YOUTH}

The most important feature of a health indicator is that it is favorably and substantially associated with health variables of interest (e.g., mental, emotional, cognitive, psychosocial, physiological, and physical health). Ideally, a single measure at the population level could provide an aggregate measure of pediatric population health. In addition to current healthstatus, it is important for health indicators to be predictive of future health. This is especially important in pediatricpopulations because it could help inform and prepare jurisdictions for the potential future burden of disease.

\section{Cardiorespiratory Fitness and Health}

CRF levels are regarded as an important health indicator $\left({ }^{17}\right)$. It is noteworthy that CRF is meaningfully associated with health, independent of PA levels, in children and youth $\left({ }^{19,32}\right)$, suggesting that the measurement of CRF provides additional insight into the health of kids, above which can be provided by PA alone. Recent research has identified that high levels of CRF are favorably associated with healthy cardiovascular and metabolic profiles among children and youth (66,70-72). The strength of the associations seems to be stronger for CRF when compared with objective measures of PA levels in children and youth $\left({ }^{73,74}\right)$. Similarly, several studies have shown considerably stronger inverse relation between CRF and mortality than between PA and mortality among adult populations $\left({ }^{75,76}\right)$. Overall, the measurement of CRF seems to provide a good summative indication of the ability of numerous bodily systems and organs (e.g.,cardiorespiratory, musculoskeletal, endocrine-metabolic, psychoneurological, hematocirculatory) involved in human movement.

The findings discussed in the previous paragraph used a variety of laboratory-based and field-based methods to measure CRF. A recent systematic review of the literature focused on the associations between 20mSRT performance and health indicators among school-aged children and youth $\left({ }^{77}\right)$. The review identified 142 studies representing more than 300,000 children and youth from 32 countries. The results indicated that $20 \mathrm{mSRT}$ performance was favorably associated with indicators of cardiometabolic, anthropometric, cognitive, and psychosocial health. Furthermore, there was limited but consistent evidence supporting favorable associations between $20 \mathrm{mSRT}$ performance and self-esteem, quality of life, and mental health $\left({ }^{77}\right)$. The systematic review concluded that the 20mSRT is an important indicator of holistic health among children and youth. Those who perform better on the $20 \mathrm{mSRT}$ have better overall health as compared with those who do not perform well. 


\section{Cardiorespiratory fitness and future health}

A systematic review of 42 longitudinal studies that assessed the relationship between fitness levels in children and future health has provided further insight into the importance of CRF $\left({ }^{18}\right)$. The review concluded that there was strong evidence suggesting that high levels of CRF in childhood predicts a healthy cardiovascular risk profile (i.e., lower levels of blood lipids, blood pressure, and overall and central adiposity) in adulthood. There was moderate evidence supporting CRF levels in childhood as a predictor of future metabolic syndrome and arterial stiffness. Lastly, moderate evidence supported increases in CRF being inversely associated with changes in blood lipids and lipoproteins in adulthood. Furthermore, these results have been supported by a large Swedish cohort study of more than 700,000 adolescents with a median follow-up of 29-34 yr, which identified that low CRF in adolescence was significantly associated with an increased risk of myocardial infarction $\left({ }^{78}\right)$ and early mortality $\left({ }^{79}\right)$ in adulthood. Together, these findings support the notion that CRF levels among children and youth are not only an indicator of current health, but also a potential indicator of future population disease burden.

\section{Cardiorespiratory fitness standards}

As described previously, there are two different types of standards used to interpret CRF results - criterion referenced and normative referenced. Of these, criterion-referenced standards provide a way to determine the amount of CRF associated with good health (e.g., healthy cardiometabolic profile). Recently, a review of criterionreferenced standards for CRF identified 10 different sets of standards for children and youth, all of which produced different percentage estimates of children and youth with healthy CRF $\left({ }^{64}\right)$. Consequently, it was recommended that the results from a meta-analysis of seven criterion-referenced standards could be used as interim international criterion-referenced standards. The findings highlighted that boys and girls (aged 8-18 yr) should attain the minimum standards of 42 and $35 \mathrm{~mL} \cdot \mathrm{kg}^{-1} \cdot \mathrm{min}^{-1}$, respectively because anything below these standards should raise a red flag $\left({ }^{67}\right)$. A recent Canadian study applied these international standards in children aged 8-12 yr and identified that nearly all Canadian girls have healthy CRF, whereas the percentage of boys with healthy CRF declined substantially with age $\left.{ }^{80}\right)$. Thus, it is possible that these results highlight a limitation of the standards, which may be a result of using a single sex-specific standard for all age groups with only cardiometabolic criteria. As a result, there is a need for more research in this area.

International normative-referenced standards have been developed using a sample of 1,142,026 children and youth, representing 50 different countries $\left({ }^{47}\right)$. These standards provide a way to determine how children and youth perform on the $20 \mathrm{mSRT}$ compared with their peers by identifying their percentile rank. These types of standards, whether international $\left({ }^{47}\right)$ or national $\left({ }^{56-63}\right)$, could help complement criterion-referenced standards, especially in younger children, of whom most probably have a healthy cardiometabolic profile, equating to high percentages with healthy CRF $\left({ }^{64,80}\right)$. Together, criterion- referenced and normative-referenced standards could be used in research, physical education, and clinical settings to screen for pediatric populations at risk of poor health and to compare the health of children and youth across various jurisdictions.

\section{POPULATION-BASED SURVEILLANCE UTILITY}

The implementation of effective population-based surveillance at the national and international level could provide insight into the effectiveness of broad public policy and interventions aimed at improving health. There are two analytical strategies available to help optimize the use of surveillance data. First, data could be compared across jurisdictions at similar time points to help identify healthy and unhealthy populations. As a result, policymakers in regions with unhealthy populations could learn and take similar policy-based approaches as comparable healthy populations. Second, repeated measures in the same population could identify temporal trends in health. Indeed, temporal trends may help monitor the impact of implemented policies aimed at improving health in a population, and they could help predict the health of future generations. It also is beneficial to compare similar health temporal trends across jurisdictions, although these analyses are complex and not common. 


\section{Comparisons of Surveillance Measures Across Countries}

Recently, a published study provided a comparison of 20mSRT performance across 50 countries, which currently represents the largest international effort to compare CRF levels among children and youth. Results from this study indicated that children and youth from countries in Northern Europe and Africa were the best 20mSRT performers, whereas those from South American countries were generally the worst $20 \mathrm{mSRT}$ performers $\left({ }^{81}\right)$. These findings were based on a systematic review and analysis of pooled, aggregate 20mSRT results from 177 published studies, representing a fairly comprehensive surveillance effort. By comparing these results with more complex PA surveillance efforts, it is possible to identify the accuracy of these results given the interconnected relation between $\mathrm{CRF}$ and PA $\left({ }^{30}\right)$.

An approach used to help understand differences in the PA levels of children and youth across countries is through the Active Healthy Kids Global Alliance's report cards on the physical activity of children and youth global matrix project $\left({ }^{82}\right)$. Through this project, researchers across countries cooperate to review and synthesize recent data on country-based PA levels among children and youth using harmonized methods. As a result, this project has produced report cards for 38 countries that have helped identify patterns of low PA levels in some Asian, North American, and South American countries, and higher PA levels in some Northern European, Oceanic, and African countries ${ }^{82}$ ). These results are consistent with findings from the recent 50 -country comparison of $20 \mathrm{mSRT}$ performance scores among children and youth $\left({ }^{81}\right)$.

Nationally representative objective measures of PA levels among children and youth are rare and only available for a few high-income countries (i.e., parts of North America, Europe, and Oceania). The International Children's Accelerometry Database (ICAD) is a data-sharing project that has generated the largest dataset of objective estimates of PA among children and youth $\left(^{83}\right)$. Results from ICAD across 10 countries support findings that PA levels are higher among children and youth in Northern European countries when compared with their counterparts in North America $\left(^{84}\right)$. Objective measures of PA also are available for more than 3000 youth from 10 European countries through the Healthy Lifestyle in Europe by Nutrition in Adolescence (HELENA) study. The HELENA study demonstrated a European gradient where youth from Northern European countries were more active than their Southern European counterparts $\left.{ }^{(85,86}\right)$. This result was replicated for CRF using $20 \mathrm{mSRT}$ scores available from 23 European countries $\left({ }^{81}\right)$. Another analysis using HELENA data found that differences in CRF across European countries were attenuated when controlling for PA levels, highlighting the interconnected relation between CRF and objectively measured PA ${ }^{85}$ ). Together, these findings suggest that 20mSRT scores provide a fairly accurate reflection of objectively measured PA at the population level. Thus, if measuring PA using objective methods is not possible because of financial, economic, or human resource constraints, the measurement of CRF using the $20 \mathrm{mSRT}$ and analyzed with health-related and performance-related methods could be a feasible alternative. Using the 20mSRT for surveillance of population health would be particularly important in low-income and middle-income countries given that these countries may be in the midst of a physical activity transition, which may forecast future health consequences $\left({ }^{81,87}\right)$. Furthermore, in countries with established objective PA surveillance systems (e.g., Canada, United States, United Kingdom), the addition of CRF surveillance would be valuable because CRF predicts health independent of PA, and this would, therefore, provide additional information on health above and beyond what can be obtained by measuring PA alone.

\section{Temporal Trends in Surveillance Measures}

Temporal trends using consistent objective measures of PA over several years are available only in some highincome countries (e.g., Japan $\left({ }^{88}\right)$, Czech Republic $\left({ }^{89}\right)$, Canada $\left({ }^{90}\right)$, Sweden $\left({ }^{11,91}\right)$ ) but not internationally. This is partly because the methods used to measure PA have changed considerably over the years, and the use of accelerometers and other objective measures in the surveillance of pediatric PA levels is relatively new. Furthermore, temporal trends using subjective PA measures could be problematic because the bias associated with these measures may have systematically changed over time. Given that CRF assesses an individual's physiological 
response to their total PA profile, the best approach to fully understand trends in PA in most countries and globally is probably through the assessment of CRF using the widely adopted 20mSRT field-based assessment test. The $20 \mathrm{mSRT}$ has been conducted using similar protocols since its inception, providing a way to calculate consistently reported temporal trend data. Thus, trends in CRF using the 20mSRT can be dated back to the late 1980s, with a study published in 2003 having reported an average global decline in performance of $0.43 \%$ per annum across 129,882 children and youth from 11 countries $\left({ }^{48}\right)$. A follow-up study using an updated dataset to the 2003 study compared 20mSRT performance of 965,264 children and youth from 19 countries between 1981 and $2015\left({ }^{92}\right)$. The included countries represented high-income and upper-middle-income countries supporting the need for more data in low-income and middle-income countries. The study results suggested that time trends in CRF were not uniform across countries, with all but two countries (Japan and Brazil) demonstrating declines in recent decades. However, a general slowing of the decline existed among most countries where temporal trends in CRF seem to have stabilized, at least in high-income and upper-middle-income countries, in recent years $\left({ }^{92}\right)$. This finding is encouraging and may suggest that the plethora of interventions and policies implemented in these countries might be having an impact on slowing the decline in childhood CRF levels. Nevertheless, there remains a need to explore new policies and interventions aimed at improving CRF and PA levels in these populations - insights that Japan and Brazil might be able to provide.

\section{NOVEL POPULATION HEALTH SURVEILLANCE STRATEGIES}

The measurement of CRF (i.e., 20mSRT) is cost effective and would be easy to administer at the population level. As a result, CRF surveillance provides several opportunities in the scientific research, physical education, and clinical settings.

\section{The Scientific Research Setting}

An important issue in 20mSRT research is that three known protocol variants are extant, and results can be reported in multiple performance metrics $\left({ }^{48}\right)$. Although data conversion techniques are available $\left({ }^{47}\right)$, they are time consuming and problematic. It is important that researchers report 20mSRT results following the Tomkinson recommendations to improve data commensurability $\left({ }^{47}\right)$. To achieve this goal, a recent publication has recommended the development of an online 20mSRT data repository where researchers around the world can share their 20mSRT data in a consistent way to help improve surveillance efforts $\left({ }^{81}\right)$. In return, the Web site (www.activehealthykids.org/kids-fit-guide/) would compute a results sheet comparing the participants' performance to national and international normative- referenced and criterion-referenced standards, providing the researcher with valuable analytical support. These data would be securely stored and used to improve CRF surveillance efforts by updating regional, national, and international CRF trends, cross-country comparisons, and normative-referenced data. In addition, the database would provide rich data for researchers worldwide to analyze and use in their respective research projects. Being free and simple to use, this data repository could help bridge the gap in surveillance efforts in low-income and middle-income countries. The Web site is currently under construction in preparation for its official launch in early 2018.

\section{The Physical Education Setting}

The school setting remains one of the most promising locations to implement consistent national and international surveillance for school-aged children and youth $\left({ }^{93}\right)$. School-based surveillance efforts also could be considered an effective population-based intervention. For instance, the commitment to consistent periodic surveillance surveys places importance and develops a conversation around particular measures. This is evident in school settings, where national standardized testing in some countries reinforces the importance of certain academic skills over others. Although the 20mSRT has been used successfully in the school setting for years, only a few countries and jurisdictions have committed to CRF surveillance in schools (e.g., Hungary $\left({ }^{94}\right)$, certain states in the United States $\left({ }^{49}\right)$, South Korea $\left({ }^{95}\right)$, Japan $\left({ }^{96}\right)$, China $\left({ }^{96}\right)$ ). Of these countries, Slovenia provides a good example of how fitness surveillance can lead to improved health. 
Slovenia collects national CRF and other fitness data for all children and youth (aged 6-19 yr) through a surveillance initiative called SLOfit $\left({ }^{97}\right)$. The SLOfit initiative has been mandatory for all primary and secondary schools for more than $30 \mathrm{yr}$. Through mandatory annual surveillance of standardized fitness measures, researchers and policymakers were able to identify a declining trend in youth fitness from 1990 to 2010. To mitigate this trend, Slovenia implemented a national health-promoting PA intervention called Healthy Lifestyle in the 2010/2011 school year, which provided children and youth with two optional additional hours of PA per week. As a result, the fitness levels of Slovenian children and youth have steadily improved since 2011. Furthermore, a recent report compared PA levels across 38 countries (representing six continents) and reported that Slovenia was ranked number one in overall national PA levels among youth $\left({ }^{82}\right)$. The Slovenia case study highlights the importance of surveillance in guiding and monitoring the impact of health-promoting interventions and policies - an example that other countries could adopt.

\section{The Clinical Setting}

In adults, the use of CRF assessments in clinical settings has been proposed by the American Heart Association as an important vital sign that could help improve patient risk classification for adverse health outcomes and provide a better way to inform patient management $\left({ }^{5}\right)$. Similar to adults, the use of CRF assessments in children and youth could be used as a clinical vital sign in at-risk patients (e.g., obesity, diabetes mellitus, heart conditions, etc.) to help improve risk classification, monitor changes in health status, and help prescribe evidence-informed lifestyle management. The $20 \mathrm{mSRT}$ is a maximal assessment that is not recommended for at-risk patients; thus, less valid submaximal tests such as the YMCA submaximal bicycle test $\left({ }^{98}\right)$, PWC170 $\left({ }^{99}\right)$, child-adapted Astrand-Ryhming test $\left({ }^{100}\right)$, mCAFT $\left({ }^{101}\right)$, and HALO submaximal treadmill test $\left({ }^{102}\right)$ could be used for these populations to provide a measurement of CRF. The consistent collection and reporting of CRF data for at-risk children and youth, in addition to other health measures, could provide valuable surveillance data for scientists to research the link between changes in CRF and health outcomes in these populations. This approach also lends itself well to the current ACSM Exercise is Medicine ${ }^{\circledR}$ movement $\left({ }^{103}\right)$ by providing clinicians with a way to objectively monitor PA levels in their patients through the measurement of CRF.

\section{IMPORTANCE OF GUIDELINES FOR PUBLIC HEALTH}

The development and distribution of guidelines provides a method to set a benchmark that is widely accepted and easily communicated across all sectors of the population. Given that CRF is a holistic indicator of health among children and youth that has strong utility for population-based surveillance, developing public health guidelines may be a beneficial approach to help advance CRF surveillance.

\section{Cardiorespiratory Fitness Guidelines}

The interim international criterion-referenced standards of 42 and $35 \mathrm{~mL} \cdot \mathrm{kg}^{-1} \cdot \mathrm{min}^{-1}$ for boys and girls aged 8-18 yr $\left({ }^{67}\right)$, respectively, represent the best available CRF standards with which to identify children and youth with good health despite there

\begin{tabular}{|c|c|c|c|c|c|c|}
\hline \multirow[b]{2}{*}{ Age (yr) } & \multicolumn{3}{|c|}{ Boys } & \multicolumn{3}{|c|}{ Girls } \\
\hline & $\begin{array}{l}\text { No. Completed } \\
\text { 20mSRT Laps }\end{array}$ & Running Speed $\left(\mathbf{k m}-\mathrm{h}^{-1}\right)$ & $\begin{array}{l}\text { International Percentage } \\
(\%) \text { Meeting Standards" }\end{array}$ & $\begin{array}{l}\text { No. Completed } \\
\text { 20mSRT Laps }\end{array}$ & Running Speed (km-h"“') & $\begin{array}{l}\text { International Percentage (\%) } \\
\text { Meeting Standards" }\end{array}$ \\
\hline 8 & 7 & 8.5 & & 7 & 8.5 & \\
\hline 9 & 15 & 9.0 & 93.0 & 7 & 8.5 & 99.9 \\
\hline 10 & 15 & 9.0 & 87.2 & 7 & 8.5 & 99.6 \\
\hline 11 & 23 & 9.5 & 78.5 & 7 & 8.5 & 98.6 \\
\hline 12 & 31 & 10.0 & 72.3 & 7 & 8.5 & 93.9 \\
\hline 13 & 40 & 10.5 & 70.3 & 15 & 9.0 & 88.3 \\
\hline 14 & 40 & 10.5 & 62.8 & 15 & 9.0 & 78.6 \\
\hline 15 & 49 & 11.0 & 62.3 & 23 & 9.5 & 67.2 \\
\hline 16 & 49 & 11.0 & 56.2 & 31 & 10.0 & 54.1 \\
\hline 17 & 59 & 11.5 & 51.7 & 31 & 10.0 & 43.6 \\
\hline 18 & 59 & 11.5 & & 40 & 10.5 & \\
\hline
\end{tabular}


being a need for more research. The interim standards have been converted to $20 \mathrm{mSRT}$ laps, and the corresponding international percentages of children and youth that meet the standards have been estimated (Table 2). In addition, the international normative-referenced standards could be used to establish cut points for low, medium, and high 20mSRT performance to complement the criterion- referenced standards $\left({ }^{47}\right)$ (Table 3). Combined, these 20mSRT values currently represent the best available evidence from which to build CRF guidelines among children and youth.

The development of CRF guidelines could provide many benefits. For instance, CRF guidelines could be an effective knowledge translation tool to communicate the importance of CRF for current and future health. The guidelines would help support surveillance efforts by communicating the minimum level of fitness needed for good health, similar to the PA guidelines. These guidelines would be effective for screening initiatives in the school and clinical settings to identify those at risk of poor health. Screening efforts could help identify those who need support in increasing PA levels through exercise prescription or lifestyle management. Furthermore, the establishment of an online 20mSRT CRF data repository would allow for the guidelines to be progressively assessed and modified as emerging evidence is collected.

\section{How to Meet the Cardiorespiratory Fitness Guidelines}

Although CRF has an important genetic component $\left({ }^{30}\right)$, it has been described as a reflection of an individual's PA participation in recent weeks or months $\left({ }^{104}\right)$. Research supports the notion that regular PA, especially at moderate and vigorous intensities, could produce a significant response in CRF levels. More specifically, a 12wk training program can induce an 8\%-9\% ( 20 normative-referenced percentile points) increase in CRF among children and youth independent of sex, age, and maturation $\left({ }^{33}\right)$. Thus, it is likely that those who do not meet the CRF guidelines are not physically active enough to support a healthy CRF level. As a result, when screening pediatric populations using the CRF guidelines, it would be reasonable to prescribe PA guidelines to those with low CRF as a way to improve health, and to encourage continued PA in those with good CRF to maintain health. In addition, it is important to encourage healthy lifestyle choices to maintain healthy body weight and avoid excess body fatness $\left({ }^{42}\right.$ ). This approach also could serve as an important education tool to highlight the importance of PA and to track progress through CRF levels.

\section{PERSPECTIVES FOR PROGRESS}

To develop and expand CRF surveillance initiatives, there are several priority areas for future research:

1. This review provides an opinion that developing CRF guidelines could be an important strategy to help advance public health knowledge and research on CRF. Because this opinion may lack consensus throughout the public health and research communities, it would be important to develop a consensus statement on CRF guidelines.

2. This review demonstrates the importance of the $20 \mathrm{mSRT}$ as an indicator of current and future health among children and youth.

\begin{tabular}{|c|c|c|c|c|c|c|}
\hline \multirow[b]{2}{*}{ Age (yr) } & \multicolumn{3}{|c|}{ Boys } & \multicolumn{3}{|c|}{ Girls } \\
\hline & $P_{20}($ Low CRF) & $\mathbf{P}_{50}$ (Medium CRF) & PRO (High CRF) & $P_{20}($ Low CRF $)$ & $\mathbf{P}_{50}$ (Medium CRF) & $\mathbf{P} * \mathbf{0}($ High CRF $)$ \\
\hline 9 & $20(9.31)$ & $32(10.03)$ & $45(10.75)$ & $17(9.13)$ & $26(9.72)$ & $36(10.31)$ \\
\hline 10 & $21(9.35)$ & $33(10.13)$ & $47(10.90)$ & $17(9.10)$ & $27(9.75)$ & $38(10.40)$ \\
\hline 11 & $22(9.41)$ & $36(10.25)$ & $51(11.09)$ & $16(9.09)$ & $28(9.78)$ & $40(10.48)$ \\
\hline 12 & $24(9.53)$ & $39(10.47)$ & $57(11.40)$ & $16(9.08)$ & $28(9.83)$ & $41(10.57)$ \\
\hline $\begin{array}{l}13 \\
14\end{array}$ & $\begin{array}{l}26(9.72) \\
29(9.88)\end{array}$ & $\begin{array}{l}44(10.73) \\
48(10.96)\end{array}$ & $\begin{array}{l}64(11.75) \\
70(12.04)\end{array}$ & $\begin{array}{l}17(9.09) \\
17(9.11)\end{array}$ & $\begin{array}{l}29(9.86) \\
29(9.89)\end{array}$ & $\begin{array}{r}42(10.63) \\
43(10.67)\end{array}$ \\
\hline 15 & $31(10.01)$ & $52(11.13)$ & $74(12.25)$ & $17(9.12)$ & $30(9.91)$ & $44(10.70)$ \\
\hline 16 & $33(10.11)$ & 54 01.27) & 78 (12.42) & $17(9.13)$ & $30(9.93)$ & $4400.73)$ \\
\hline 17 & $35(10.22)$ & $57(11.41)$ & $81(12.60)$ & $17(9.14)$ & $30(9.96)$ & $45(10.77)$ \\
\hline
\end{tabular}


Given the lack of temporal data among children and youth in low-income and middle-income countries (parts of South America, Africa, and Asia) there is a need for coordinated efforts to measure the current state of CRF in these countries and worldwide. This could be carried out through an international survey on the $20 \mathrm{mSRT}$ performance of children and youth. These data would be vital for identifying populations in poor health and at risk of potential elevated disease burden in the future as well as for monitoring trends over time.

In conclusion, we recommend a paradigm shift that includes CRF surveillance among children and youth. CRF surveillance could supplement current PA surveillance, and in some cases, CRF could replace the surveillance of PA, especially in countries with financial, human resource, or economic constraints. Furthermore, the population-based measurement of CRF could provide a method to better understand the link between PA levels and health among children and youth at the population level. To expand the utility of CRF surveillance, there is a need to establish clear CRF guidelines to provide a uniform interpretation of CRF among children and youth. The use of consistent and periodic CRF surveillance could help guide and evaluate health-promoting policies and interventions aimed at reducing NCD burden and improving overall health in the population. Perhaps sufficient investment in CRF surveillance could be the first step toward increasing healthy life expectancy, where people can live longer without NCDs and disability — bridging the gap between increasing life expectancy and healthy life expectancy.

\section{References}

1. GBD 2015 Mortality and Causes of Death Collaborators. Global, regional, and national life expectancy, all-cause mortality, and causespecific mortality for 249 causes of death, 1980-2015: a systematic analysis for the Global Burden of Disease Study 2015. Lancet. 2016; 388(10053): 1459-544.

2. Salomon JA, Wang H, Freeman MK, et al. Healthy life expectancy for 187 countries, 1990-2010: a systematic analysis for the Global Burden Disease Study 2010. Lancet. 2012; 380(9859):2144- 62.

3. Bloom DE, Cafiero ET, Jane-Llopis E, et al. The Global Economic Burden of Non-Communicable Diseases. Geneva (Switzerland): World Economic Forum; 2011. p. 48.

4. Fletcher GF, Blair SN, Blumenthal J, et al. Statement on exercise. Benefits and recommendations for physical activity programs for all Americans. A statement for health professionals by the Committee on Exercise and Cardiac Rehabilitation of the Council on Clinical Cardiology, American Heart Association. Circulation. 1992; 86(1):340-4.

5. Ross R, Blair SN, Arena R, et al. Importance of assessing cardiorespiratory fitness in clinical practice: a case for fitness as a clinical vital sign: a scientific statement from the American Heart Association. Circulation. 2016; 134(24):e653-99.

6. Lee IM, Shiroma EJ, Lobelo F, et al. Effect of physical inactivity on major non-communicable diseases worldwide: an analysis of burden of disease and life expectancy. Lancet. 2012; 380(9838):219- 29.

7. Berenson GS, Srinivasan SR, Bao W, Newman WP 3rd, Tracy RE, Wattigney WA. Association between multiple cardiovascular risk factors and atherosclerosis in children and young adults. The Bogalusa Heart Study. N. Engl. J. Med. 1998; 338(23):1650-6.

8. Dollman J, Norton K, Norton L. Evidence for secular trends in children's physical activity behaviour. Br. J. Sports Med. 2005; 39(12):892-7.

9. Ekelund U, Tomkinson G, Armstrong N. What proportion of youth are physically active? Measurement issues, levels and recent time trends. Br. J. Sports Med. 2011; 45:859-65. 
10. Booth VM, Rowlands AV, Dollman J. Physical activity temporal trends among children and adolescents. J. Sci. Med. Sport. 2015; 18(4):418-25.

11. Ortega FB, Konstabel K, Pasquali E, et al. Objectively measured physical activity and sedentary time during childhood, adolescence and young adulthood: a cohort study. PLoS One. 2013; 8(4):e60871.

12. Tomkinson GR, Olds TS. Secular changes in pediatric aerobic fitness test performance: the global picture. Med. Sport Sci. 2007; 50:46-66.

13. Tremblay MS, Shields M, Laviolette M, Craig CL, Janssen I, Connor Gorber S. Fitness of Canadian children and youth: results from the 2007-2009 Canadian Health Measures Survey. Health Rep. 2010; 21(1):7-20.

14. Nelson MC, Neumark-Stzainer D, Hannan PJ, Sirard JR, Story M. Longitudinal and secular trends in physical activity and sedentary behavior during adolescence. Pediatrics. 2006; 118(6):e1627.

15. Alwan A, MacLean DR, Riley LM, et al. Monitoring and surveillance of chronic non-communicable diseases: progress and capacity in highburden countries. Lancet. 2010; 376(9755): 1861-8.

16. Hallal PC, Andersen LB, Bull F, Guthold R, Haskell W, Ekelund U; Lancet Physical Activity Series Working Group. Global physical activity levels: surveillance progress, pitfalls, and prospects. Lancet. 2012; 380(9838):247-57.

17. Ortega FB, Ruiz JR, Castillo MJ, Sjostrom M. Physical fitness in childhood and adolescence: a powerful marker of health. Int. J. Obes. (Lond). 2008; 32:1-11.

18. Ruiz JR, Castro-Pinero J, Artero EG, et al. Predictive validity of healthrelated fitness in youth: a systematic review. Br. J. Sports Med. 2009; 43(12):909-23.

19. Eklund U, Anderssen SA, Froberg K, et al. Independent associations of physical activity and cardiorespiratory fitness with metabolic risk factors in children: the European youth heart study. Diabetologia. 2007; 50:1832-40.

20. Institute of Medicine (IOM). Fitness Measures and Health Outcomes in Youth. Washington (DC): The National Academies Press; 2012. p. 260.

21. Pate RR, Welk GJ, McIver KL. Large-scale youth physical fitness testing in the United States: a 25year retrospective review. Pediatr. Exerc. Sci. 2013; 25:515-23.

22. Ruiz JR, Castro-Pinero J, Espana-Romero V, et al. Field-based fitness assessment in young people: the ALPHA health-related fitness test battery for children and adolescents. Br. J. Sports Med. 2011; 45(6):518-24.

23. Mayorga-Vega M, Aguilar-Soto P, Viciana J. Criterion-related validity of the 20-M shuttle run test for estimating cardiorespiratory fitness: a metaanalysis. J. Sports Sci. Med. 2015; 14:536-47.

24. Ruiz JR, Silva G, Oliveira N, Ribeiro JC, Oliveira JF, Mota J. Criterionrelated validity of the 20-m shuttle run test in youths aged 13-19 years. J. Sports Sci. 2009; 27(9):899-906.

25. Castro-Pinero J, Artero EG, Espana-Romero V, et al. Criterion-related validity of field-based fitness tests in youth: a systematic review. Br. J. Sports Med. 2010; 44(13):934-43.

26. Tomkinson GR, Olds TS. Field tests of fitness. In: Armstrong N, van Mechlen W, editors. Paediatric Exercise Science and Medicine. New York (NY): Oxford University Press; 2008. p. 109-28.

27. Ortega FB, Artero EG, Ruiz JR, et al. Reliability of health-related physical fitness tests in European adolescents. The HELENA Study. Int. J. Obes. (Lond). 2008; 32(Suppl. 5):S49-S57.

28. Artero EG, Espana-Romero V, Castro-Pinero J, et al. Reliability of fieldbased fitness tests in youth. 
Int. J. Sports Med. 2011; 32(3):159-69.

29. Bouchard C, Shephard RJ. Physical activity, fitness and health: the model and key concepts. In:

Bouchard C, Shephard RJ, Stephens T, editors. Physical Activity, Fitness and Health. Champaign (IL): Human Kinetics; 1994. p. 77-88.

30. Malina RM. Physical activity and fitness: pathways from childhood to adulthood. Am. J. Hum. Biol. $2001 ; 13: 162-72$.

31. Ruiz JR, Rizzo NS, Hurtig-Wennlof A, Ortega FB, Warnberg J, Sjostrom M. Relations of total physical activity and intensity to fitness and fatness in children: the European Youth Heart Study. Am. J. Clin. Nutr. 2006; 84(2):299-303.

32. Steele RM, Brage S, Corder K, Wareham NJ, Ekelund U. Physical activity, cardiorespiratory fitness, and the metabolic syndrome in youth. J. Appl. Physiol. 2008; 105(1):342-51.

33. Armstrong N, Tomkinson GR, Ekelund U. Aerobic fitness and its relationship to sport, exercise training and habitual physical activity during youth. Br. J. Sports Med. 2011; 45:849-58.

34. Armstrong N. Aerobic fitness and physical activity in children. Pediatr. Exerc. Sci. 2013; 25:548-60.

35. Kemper HCG, van Mechelen W. Physical fitness testing of children: a European perspective. Pediatr. Exerc. Sci. 1996; 8(3):201-14.

36. Morrow JR Jr, Zhu W, Franks BD, Meredith MD, Spain C. 1958-2008: 50 years of youth fitness tests in the United States. Res. Q. Exerc. Sport. 2009; 80(1): 1-11.

37. Ortega FB, Ruiz JR, Espana-Romero V, et al. The International Fitness Scale (IFIS): usefulness of self-reported fitness in youth. Int. J. Epidemiol. 2011; 40:701-11.

38. Sanchez-Lopez M, Martinez-Vizcaino V, Garcia-Hermoso A, JimenezPavon D, Ortega FB. Construct validity and test-retest reliability of the International Fitness Scale (IFIS) in Spanish children aged 9-12 years. Scand. J. Med. Sci. Sports. 2015; 25(4):543-51.

39. Rowland TW. Does peak VO2 reflect VO2max in children? Evidence from supramaximal testing. Med. Sci. Sports Exerc. 1993; 25(6):689-93.

40. Armstrong N, Barker AR. Oxygen uptake kinetics in children and adolescents: a review. Pediatr. Exerc. Sci. 2009; 21:130-47.

41. Buskirk E, Taylor HL. Maximal oxygen intake and its relation to body composition, with special reference to chronic physical activity and obesity. J. Appl. Physiol. 1957; 11(1):72-8.

42. Lloyd LK, Bishop PA, Walker JL, Sharp KR, Richardson MT. The influence of body size and composition on FITNESSGRAM ${ }^{\circledR}$ test performance and the adjustment of FITNESSGRAM ${ }^{\circledR}$ test scores for skinfold thickness in youth. Meas. Phys. Edu. Exerc. Sci. 2009; 7(4):205-26.

43. Welsman JR, Armstrong N, Nevill AM, Winter EM, Kirby BJ. Scaling peak VO2 for differences in body size. Med. Sci. Sports Exerc. 1996; 28(2):259-65.

44. Leger L, Lambert J, Goulet A, Rowan C, Dinelle Y. Aerobic capacity of 6- to 17-year-old Quebecois-20 meter shuttle run test with 1 minute stages [Article in French]. Can. J. Appl. Sport Sci. 1984; 9(2):64-9.

45. Leger LA, Mercier D, Gadoury C, Lambert J. The multistage 20 metre shuttle run test for aerobic fitness. J. Sports Sci. 1988; 6(2):93-101.

46. Olds TS, Tomkinson GR, Leger L, Cazorla G. Worldwide variation in the performance of children 
and adolescents: an analysis of 109 studies of the 20 -m shuttle run test in 37 countries. J. Sports Sci. 2006; 24(10):1025-38.

47. Tomkinson GR, Lang JJ, Tremblay MS, et al. International normative $20 \mathrm{~m}$ shuttle run values from 1 142026 children and youth representing 50 countries. Br. J. Sports Med. 2017; 51(21): 1545-54.

48. Tomkinson GR, Leger LA, Olds TS, Cazorla G. Secular trends in the performance of children and adolescents (1980-2000): an analysis of 55 studies of the $20 \mathrm{~m}$ shuttle run test in 11 countries. Sports Med. 2003; 33(4):285-300.

49. Welk GJ, Bai Y, Saint-Maurice PF, Allums-Featherston K, Candelaria N. Design and evaluation of the NFL PLAY 60 FITNESSGRAM partnership project. Res. Q. Exerc. Sport. 2016; 87(1): 1-13.

50. Melo X, Santa-Clara H, Almeida JP, et al. Comparing several equations that predict peak VO2 using the 20-m multistage-shuttle run-test in 8-10-year-old children. Eur. J. Appl. Physiol. 2011; 111(5):839-49.

51. Moreira C, Santos R, Ruiz JR, et al. Comparison of different $\mathrm{VO}(2 \max )$ equations in the ability to discriminate the metabolic risk in Portuguese adolescents. J. Sci. Med. Sport. 2011; 14(1):79-84.

52. Barnett A, Chan LYS, Bruce IC. A preliminary study of the 20-m multistage shuttle run as a predictor of peak VO2 in Hong Kong Chinese students. Pediatr. Exerc. Sci. 1993; 5(1):42-50.

53. Matsuzaka A, Takahashi Y, Yamazoe M, et al. Validity of the multistage 20-m shuttle-run test for Japanese children, adolescents, and adults. Pediatr. Exerc. Sci. 2004; 16(2): 113-25.

54. Mahar MT, Welk GJ, Rowe DA, et al. Development and validation of a regression model to estimate VO2peak from PACER 20-m shuttle run performance. J. Phys. Act. Health. 2006; 3(Suppl. 2):S34-S46.

55. Ruiz JR, Ramirez-Lechuga J, Ortega FB, et al. Artificial neural networkbased equation for estimating VO2max from the $20 \mathrm{~m}$ shuttle run test in adolescents. Artif. Intell. Med. 2008; 44:233-45.

56. Catley MJ, Tomkinson GR. Normative health-related fitness values for children: analysis of 85347 test results on 9-17-year-old Australians since 1985. Br. J. Sports Med. 2013; 47:98-108.

57. Sandercock G, Voss C, Cohen D, Taylor M, Stasinopoulos DM. Centile curves and normative values for the twenty metre shuttle-run test in English schoolchildren. J. Sports Sci. 2012; 30(7):679-87.

58. Santos R, Mota J, Santos DA, Silva AM, Baptista F, Sardinha LB. Physical fitness percentiles for Portuguese children and adolescents aged 10-18 years. J. Sports Sci. 2014; 32(16):1510-8.

59. Sauka M, Priedite IS, Artjuhova L, et al. Physical fitness in northern European youth: reference values from the Latvian Physical Health in Youth Study. Scand. J. Public Health. 2011; 39(1):35-43.

60. Tambalis KD, Panagiotakos DB, Psarra G, et al. Physical fitness normative values for 6-18-year-old Greek boys and girls, using the empirical distribution and the lambda, mu, and sigma statistical method. Eur. J. Sport Sci. 2016; 16(6):736-46.

61. De Miguel-Etayo P, Gracia-Marco L, Ortega FB, et al. Physical fitness reference standards in European children: the IDEFICS study. Int. J. Obes. (Lond). 2014; 38(Suppl. 2):S57-S66.

62. Ortega FB, Artero EG, Ruiz JR, et al. HELENA study. Physical fitness levels among European adolescents: the HELENA study. Br. J. Sports Med. 2011; 45(1):20-9.

63. Ortega FB, Ruiz JR, Castillo MJ, et al. Low level of physical fitness in Spanish adolescents. Relevance for future cardiovascular health (AVENA study) [Article in Spanish]. Rev. Esp. Cardiol. 2005;58(8): 898-909.

64. Lang JJ, Tremblay MS, Ortega FB, Ruiz JR, Tomkinson GR. Review of criterion-referenced 
standards for cardiorespiratory fitness: what percentage of 1142026 international children and youth are apparently healthy? Br. J. Sports Med. [Epub ahead of print].

65. Lobelo F, Pate RR, Dowda M, Liese AD, Ruiz JR. Validity of cardiorespiratory fitness criterionreferenced standards for adolescents. Med. Sci. Sports Exerc. 2009; 41(6):1222-9.

66. Mesa JL, Ruiz JR, Ortega FB, et al. Aerobic physical fitness in relation to blood lipids and fasting glycaemia in adolescents: influence of weight status. Nutr. Metab. Cardiovasc. Dis. 2006; 16(4):285-93.

67. Ruiz JR, Cavero-Redondo I, Ortega FB, Welk GJ, Andersen LB, MartinezVizcaino V.

Cardiorespiratory fitness cut points to avoid cardiovascular disease risk in children and adolescents; what level of fitness should raise a red flag? A systematic review and meta-analysis. Br. J. Sports Med. 2016; 50:1451-8.

68. Welk GJ, Laurson KR, Eisenmann JC, Cureton KJ. Development of youth aerobic-capacity standards using receiver operating characteristic curves. Am. J. Prev. Med. 2011; 41(4 Suppl. 2):S111-S6.

69. Ruiz JR, Ortega FB, Rizzo NS, et al. High cardiovascular fitness is associated with low metabolic risk score in children: the European Youth Heart Study. Pediatr. Res. 2007; 61(3):350-5.

70. Ruiz JR, Ortega FB, Meusel D, Harro M, Oja P, Sjostrom M. Cardiorespiratory fitness is associated with features of metabolic risk factors in children. Should cardiorespiratory fitness be assessed in a European health monitoring system? The European Youth Heart Study. J. Public Health. 2006; 14(2):94-102.

71. Ruiz JR, Ortega FB, Meusel D, Sjostrom M. Traditional and novel cardiovascular risk factors in school-aged children: a call for the further development of public health strategies with emphasis on fitness. J. Public Health. 2007; 15:171.

72. Ruiz JR, Huybrechts I, Cuenca-Garcia M, et al. Cardiorespiratory fitness and ideal cardiovascular health in European adolescents. Heart. 2015; 101(10):766-73.

73. Hurtig-Wennlof A, Ruiz JR, Harro M, Sjostrom M. Cardiorespiratory fitness relates more strongly than physical activity to cardiovascular disease risk factors in healthy children and adolescents: the European Youth Heart Study. Eur. J. Cardiovasc. Prev. Rehabil. 2007; 14(4):575-81.

74. Rizzo NS, Ruiz JR, Hurtig-Wennlof A, Ortega FB, Sjostrom M. Relationship of physical activity, fitness, and fatness with clustered metabolic risk in children and adolescents: the European youth heart study. J. Pediatr. 2007; 150(4):388-94.

75. Erikssen G, Liestol K, Bjornholt J, Thaulow E, Sandvik L, Erikssen J. Changes in physical fitness and changes in mortality. Lancet. 1998; 352(9130):759-62.

76. Slattery M, Jacobs DR Jr. Physical fitness and cardiovascular disease mortality: the US railroad study. Am. J. Epidemiol. 1988; 127:571-80.

77. Lang JJ, Belanger K, Poitras V, Janssen I, Tomkinson GR, Tremblay MS. Systematic review of the relationship between $20 \mathrm{~m}$ shuttle run performance and health indicators among children and youth. J. Sci. Med. Sport. 2017. In press. doi:10.1016/j.jsams.2017.08.002.

78. Hogstrom G, Nordstrom A, Nordstrom P. High aerobic fitness in late adolescence is associated with a reduced risk of myocardial infarction later in life: a nationwide cohort study in men. Eur. Heart J. 2014; 35(44):3133-40.

79. Hogstrom G, Nordstrom A, Nordstrom P. Aerobic fitness in late adolescence and the risk of early 
death: a prospective cohort study of 1.3 million Swedish men. Int. J. Epidemiol. 2016; 45(4): 1159-68.

80. Lang JJ, Chaput JP, Longmuir PE, et al. Cardiorespiratory fitness is associated with physical literacy among Canadian children aged 8 to 12 years. BMC Public Health. accepted.

81. Lang JJ, Tremblay MS, Leger L, Olds T, Tomkinson GR. International variability in $20 \mathrm{~m}$ shuttle run performance in children and youth: who are the fittest from a 50-country comparison? A systematic literature review with pooling of aggregate results. Br. J. Sports Med. 2016. Published Online First: 20 Sept 2016. Doi:10.1136/bjsports-2016-096224.

82. Tremblay MS, Barnes JD, Gonzalez SA, et al; Global Matrix 2.0 Research Team. Global Matrix 2.0: report card grades on the physical activity of children and youth comparing 38 countries. J. Phys. Act. Health. 2016; 13(Suppl. 2):S343-S66.

83. Sherar LB, Griew P, Esliger DW, et al. International children's accelerometry database (ICAD): design and methods. BMC Public Health. 2011; 11:485.

84. Cooper AR, Goodman A, Page AS, et al. Objectively measured physical activity and sedentary time in youth: the International children's accelerometry database (ICAD). Int. J. Behav. Nutr. Phys. Act. $2015 ; 12: 113$.

85. Ortega FB, Ruiz JR, Labayen I, et al. Health inequalities in urban adolescents: role of physical activity, diet, and genetics. Pediatrics. 2014; 133(4):e884-95.

86. Ruiz JR, Ortega FB, Martinez-Gomez D, et al. Objectively measured physical activity and sedentary time in European adolescents: the HELENA study. Am. J. Epidemiol. 2011; 174(2):173-84.

87. Katzmarzyk PT, Mason C. The physical activity transition. J. Phys. Act. Health. 2009; 6(3):269-80.

88. Inoue S, Ohya Y, Tudor-Locke C, Tanaka S, Yoshiike N, Shimomitsu T. Time trends for stepdetermined physical activity among Japanese adults. Med. Sci. Sports Exerc. 2011; 43:1913-9.

89. Sigmundova D, El Ansari W, Sigmund E, Fromel K. Secular trends: a tenyear comparison of the amount and type of physical activity and inactivity of random samples of adolescents in the Czech Republic. BMC Public Health. 2011; 11:731.

90. Thompson AM, McHugh TL, Blanchard CM, et al. Physical activity of children and youth in Nova Scotia from 2001/02 and 2005/06. Prev. Med. 2009; 49:407-9.

91. Raustorp A, Ludvigsson J. Secular trends of pedometer-determined physical activity in Swedish school children. Acta Paediatr. 2007; 96:1824-8.

92. Tomkinson GT, Lang JJ, Tremblay MS. Temporal trends in the cardiorespiratory fitness of children and adolescents representing 19 high-income and upper middle-income countries between 1981 and 2014. Br. J. Sports Med. 2017. Doi: 10.1136/bjsports-2017-097982.

93. Pate RR. The case for large-scale physical fitness testing in American youth. Pediatr. Exerc. Sci. 1989; 1(4):290-4.

94. Csanyi T, Finn KJ, Welk GJ, et al. Overview of the Hungarian National Youth Fitness Study. Res. Q. Exerc. Sport. 2015; 86(Suppl. 1):S3-S12.

95. Tomkinson GR, Olds TS, Kang SJ, Kim DY. Secular trends in the aerobic fitness test performance and body mass index of Korean children and adolescents (1968-2000). Int. J. Sports Med. 2007; 28:314- 
20.

96. Macfarlane DJ, Tomkinson G. Evolution and variability in fitness test performance of Asian children and adolescents. Med. Sport Sci. 2007; 50:143-67.

97. Strel J. Analysis of the program Healthy Lifestyle for the years 2010/11 and 2011/12 [Article in Slovenian]. Ljubljana (Slovenia): Institute for Sport Planica; 2013.

98. YMCA. YMCA Fitness Testing and Assessment Manual. 4th ed. Champaign (IL): Human Kinetics; 2000. p. 247.

99. Campbell PT, Katzmarzyk P, Malina RM, Rao DC, Perusse L, Bouchard C. Prediction of physical activity and physical work capacity (PWC150) in young adulthood from childhood and adolescence with consideration of parental measures. Am. J. Hum. Biol. 2001; 13(2): 190-6.

100. Buono MJ, Roby JJ, Micale FG, Sallis JF. Predicting maximal oxygen uptake in children: modification of the Astrand-Ryhming nomogram for predicting maximal oxygen intake. Br. J. Sports Med. 1981; 15(3):182-5.

101. Weller IMR, Thomas SG, Corey PN, Cox MH. Prediction of maximal oxygen uptake from a modified Canadian aerobic fitness test. Can. J. Appl. Physiol. 1993; 18(2): 175-88.

102. Breithaupt $\mathrm{P}$, Adamo KB, Colley RC. The HALO submaximal treadmill protocol to measure cardiorespiratory fitness in obese children and youth: a proof of principle study. Appl. Physiol. Nutr. Metab. 2012; 37:308-14.

103. Lobelo F, Stoutenberg M, Hutber A. The exercise is medicine global health initiative: a 2014 update. Br. J. Sports Med. 2014; 48(22):1627-33.

104. Baquet G, Van Praagh E, Berthoin S. Endurance training and aerobic fitness in young people. Sports Med. 2003; 33(15): 1127-43. 